\title{
PERANCANGAN DATABASE E-LEARNING MANAJEMEN SYSTEM UNTUK PEMBELAJARAN PADA SEKOLAH MENENGAH PERTAMA
}

\author{
SITI KHOTIJAH \\ Program Studi Teknik Informatika, Universitas Indraprasta PGRI \\ Email: khotijah_2006@yahoo.co.id
}

\begin{abstract}
Abstrak
E-Learning Manajemen System adalah suatu perangkat lunak atau software untuk keperluan administrasi, dokumentasi, laporan sebuah kegiatan mengajar, kegiatan belajar mengajar, kegiatan secara online dan materi pelatihan. Penulisan ini adalah untuk menganalisis sistem dan merancang aplikasi E-Learning Manajemen System Berbasis Web Untuk Pembelajaran pada Sekolah Menengah Pertama (SMP) agar dapat membantu dalam proses kegiatan belajar mengajar (KBM). Dengan adanya perancangan database ini, diharapkan dapat membantu masalah yang dihadapi dalam merancang E-learning Manajemen System supaya rancangannya sesuai dengan informasi yang ingin disampaikan. Kesimpulan dari penulisan ini adalah memudahkan perancangan E-Learning Manajemen Sytem untuk pembelajaran pada sekolah menengah pertama agar komunikasi guru dan murid, pemberian materi dan pengumpulan tugas, serta memudahkan penginformasian nilai.
\end{abstract}

Kata Kunci: E-Learning, Manajemen System, Perancangan database.

\section{Pendahuluan}

\section{Latar Belakang}

Arus informasi dan teknologi yang sudah sangat berkembang saat ini mulai menampakkan peran dan fungsinya di dalam dunia pendidikan dengan didukung peran teknologi yang semakin canggih. Teknologi yang sudah canggih membuat banyak orang membuat suatu inovasi-inovasi khususnya di bidang pendidikan. E-learning membawa pengaruh terjadinya proses tranformasi pendidikan konvensional ke bentuk digital, baik secara isi maupun sistemnya. Saat ini konsep e-learning sudah banyak diterima oleh masyarakat dunia, terbukti dengan maraknya implementasi e-learning di lembaga pendidikan maupun industri.Selama ini banyak SMP melakukan pengajaran dengan cara konvensional, dimana pengajaran dilakukan dengan mengadakan pertemuan antara murid dan guru didalam kelas. Jika pertemuan dikelas antara guru dan murid tidak dilakukan maka pengajaran tidak akan terjadi. Begitu juga dengan proses transfer ilmu pengetahuan sepenuhnya hanya dilakukan didalam kelas dan jika tidak terjadi pertemuan dikelas maka proses transfer ilmu bisa saja terlambat. Dan keadaan ini terlihat sangat jelas bisa menghambat proses transfer ilmu pengetahuan yang berakibat kurang pemahaman siswa terhadap materi.

\section{Tujuan Penelitian}

Tujuan penelitian untuk memaksimalkan proses pembelajaran pada Sekolah Menengah Pertama (SMP), dimana dalam penelitian ini penulis merancang database untuk mengelola dan menstandarkan konsep pembelajaran yang dilakukan secara online melalui web dimana memudahkan proses pentransferan ilmu pengetahuan antara guru dan murid.

\section{Manfaat Penelitian}

Manfaat penelitian ini adalah memudahkan pembuatan aplikasi E-learning karena bentuk databasenya sudah dijabarkan sehingga proses pembuatan E-learning yang tujuannya menambah aktifitas belajar mengajar dengan efesiensi tempat dan waktu dapat terwujud.

\section{Tinjauan Pustaka}

\section{Sistem}

Sistem suatu sekolah berbeda-beda tergantung pada kebijakan sekolah masing-masing, secara teori mungkin sama tetapi dalam kenyataannya tergantung pada tujuan dari masing- 
masing sekolah, akan tetapi suatu sistem dapat berjalan baik atau tidak dapat dilihat dari tujuan sistem tersebut.

Tujuan utama dari sekolah adalah memberikan peningkatan mutu berbasis sekolah yang transparan dan akuntabel secara bertahap. Menurut (Kristanto, 2008) dalam Perancangan Sistem Informasi dan Aplikasinya, sistem adalah jaringan kerja dari prosedur-prosedur yang saling berhubungan, berkumpul bersama-sama untuk melakukan suatu kegiatan atau menyelesaikan suatu sasaran tertentu.

\section{Informasi}

Informasi adalah sebuah istilah yang tepat dalam pemakaian umum. Informasi dapat mengenai data mentah, data tersusun, kapasitas sebuah salura komunikasi, dan lain sebagainya. Informasi dapat didefinisikan sebagai berikut: Menurut (Sutabri, 2012), "informasi adalah data yang telah diklasifikasikan atau diinterpretasi untuk digunakan dalam proses pengambilan keputusan.". Menurut (McLeod dalam Yakub, 2012), "Informasi adalah data yang diolah menjadi bentuk yang lebih berguna bagi penerimanya".

\section{Konsep Pembelajaran E-Learning Manajemen System}

E-Learning Manajemen System adalah suatu perangkat lunak atau software untuk keperluan administrasi,dokumentasi, laporan sebuah kegiatan, kegiatan belajar mengajar dan kegiatan secara online (terhubung ke internet). Sebuah Learning Manajemen System yang kuat harus dapat melakukan hal-hal berikut (Ellis, 2009) :

1. Memusatkan dan mengotomatisasi administrasi.

2. Menggunakan Self Service dan Self Guided Services

3. dan menyampaikan konten pembelajaran secara cepat.

4. Konsolidasi pelatihan inisiatif pada sebuah scaleable web-based platform .

5. Mendukung personalisasi konten dan memungkinkan penggunaan kembali.

\section{Konsep dasar Perancangan sistem \\ Data Flow Diagram}

DFD merupakan suatu sarana yang digunakan oleh para perancang sistem untuk memberikan gambaran logika yang tidak tergantung pada perangkat lunak, perangkat keras, struktur data atau organisasi file. Dalam penggambarannya, DFD diterapkan dalam beberapa bentuk, yaitu diagram konteks dan diagram level $n$.

\section{Entity Relationship Diagram (ERD)}

ERD digunakan untuk menggambarkan hubungan antar penyimpanan data yang terdapat dalam DFD. ERD memakai sejumlah simbol untuk menggambarkan struktur dan hubungan antar data. ERD menggunakan tiga macam simbol, yaitu Entity ,Atribut, Hubungan.

\section{Basis data}

Menurut (Connolly, 2007), definisi basis data adalah kumpulan data yang dihubungkan secara bersama-sama, dan gambaran dari data yang dirancang untuk memenuhi kebutuhan informasi dari suatu organisasi. Berbeda dengan sistem file yang menyimpan data secara terpisah, pada basis data data tersimpan secara terintegrasi. Basis data bukan menjadi milik dari suatu departemen tetapi sebagai sumber daya perusahaan yang dapat digunakan bersama.

\section{MySQL}

MySQL adalah sebuah perangkat lunak sistem manajemen basis data SQL (bahasa Inggris: database management system) atau DBMS yang multithread, multi-user, dengan sekitar 6 juta instalasi di seluruh dunia. MySQL AB membuat MySQL tersedia sebagai perangkat lunak gratis dibawah lisensi GNU General Public License (GPL), tetapi mereka juga menjual dibawah lisensi komersial untuk kasus-kasus dimana penggunaannya tidak cocok dengan penggunaan GPL. 


\section{Metodologi Penelitian}

\section{Metode Studi}

Metode penelitian yang digunakan oleh peneliti adalah metode ilmiah, yaitu suatu metode penelitian berdasarkan pada data atau informasi yang dikumpulkan kemudian diteliti dan dapat diuji kebenarannya. Penulis tidak hanya mencari dan mengumpulkan data, tetapi langsung melakukan klasifikasi terhadap data tersebut, mengolah, menganalisa, membangun hipotesis menjadi teori kemudian membuat laporan hasil penelitian.

\section{Pengumpulan Data}

\section{Studi Kepustakaan}

Pengumpulan data dan informasi dari kutipan-kutipan buku-buku, hasil laporan dan bahan lainnya yang berkaitan dengan penelitian ini. Dari bahan-bahan tersebut diambil teori-teori yang dapat dijadikan landasan untuk menganalisa masalah yang ditemukan dalam penelitian.

\section{Studi Lapangan}

Studi lapangan ini penulisan lakukan untuk melihat langsung terhadap penerapan sistem pembelajaran. Dalam studi lapangan ini dipergunakan teknik pengumpulan data antara lain dengan cara Observasi dan Wawancara.

\section{Hasil dan Pembahasan}

\section{Proses Bisnis Sistem Berjalan}

Dalam pengelolaan sistem pembelajaran pada sekolah masih menggunakan sistem manual, belum memiliki perangkat lunak tersendiri . Adapun proses yang diawali dari pendaftaran siswa hingga mendapatkan jadwal pelajaran sebagai berikut :

1. Pengelolaan Jadwal Pelajaran, Jadwal Pengajar, dan Data Siswa.

Wakasek urusan kurikulum memberikan jadwal pelajaran dan data siswa ke guru yang mengajar sesuai instruksi Ketua yayasan.

2. Pengelolaan Absensi Siswa.

Tata usaha mengelola absensi siswa dan guru lalu dilaporkan kepada ketua yayasan.

3. Ujian.

Siswa menerima jadwal ujian dari wakasek urusan kurikulum yang terlebih dahulu mendapatkan instruksi dari ketua yayasan.

4. Nilai.

Guru memberikan data nilai siswa kepada tata usaha. Tata usaha mendapat perintah dari ketua yayasan untuk mengelola nilai. Setelah hasil nilai siswa keluar diberikan kepada ketua yayasan dan kemudian hasil nilai diberikan kepada siswa.

\section{Analisis Permasalahan}

Dari hasil penelitian yang penulis lakukan, maka penulis dapat menganalisa permasalahan yang ada pada sistem belajar, yaitu :

1. Pemahaman siswa dalam belajar belum optimal.

2. Kualitas pengajar.

Dari segi kualitas pengajar pendidikan di Indonesia masih rendah, apalagi dengan banyaknya tenaga pengajar yang kurang kompeten.

3. Sarana dan prasarana.

Sarana dan prasarana pendidikan di Indonesia masih sangatlah rendah, apalagi pada daerah-daerah tertinggal.

4. Efektifitas.

Banyaknya anggapan yang mengatakan bahwa pendidikan formal hanya sebagai formalitas jugalah yang menyebabkan rendahnya efektifitas pendidikan di Indonesia.

5. Efisiensi.

Efisiensi waktu dan biaya pendidikan di Indonesia masih rendah, terutama efisiensi biaya yang menyebabkan banyaknya peserta didik putus sekolah. 


\section{Alternatif Penyelesaian Masalah}

Berdasarkan masalah-masalah yang dihadapi maka penulis memberikan alternatif penyelesaian masalahnya, yaitu :

1. Meningkatkan kadar interaksi pembelajaran antara peserta didik dengan guru atau pengajar.

2. Memungkinkan terjadinya interaksi pembelajaran dari mana dan kapan saja.

3. Mempermudah penyempurnaan dan penyimpanan materi pembelajaran.

4. Perlunya pembagian penyebaran pengajar yang profesional secara merata agar tidak terjadi kesenjangan kualitas pendidikan. Karena banyak bukti yang membuktikan bahwa kualitas sekolah di Indonesia tidak merata yang menyebabkan tidak meratanya juga kualitas lulusannya.

\section{Sistem Usulan}

\section{Aturan Bisnis Sistem yang Diusulkan}

1. Proses Pendaftaran

Siswa, guru dan admin di data untuk mendapatkan password dan id. Setelah itu diproses atau di input oleh admin dan setiap masuk siswa dan guru akan mendapatkan password dan id, karena untuk masuk ke web ini guru dan siswa harus login terlebih dahulu.

2. Materi

Pengisian soal dilakukan oleh guru yang bersangkutan, serta memasukan materi yang berhubungan dengan soal kuis.

3. Soal Kuis dan Nilai

Siswa dapat mengerjakan soal kuis sesuai dengan mata pelajaran yang diberikan guru bidang studi masing-masing. Selanjutnya siswa akan mendapat nilai yang di peroleh siswa setelah selesai menjawab seluruh soal kuis yang diberikan.

\section{Dekomposisi Fungsi Sistem yang Diusulkan}

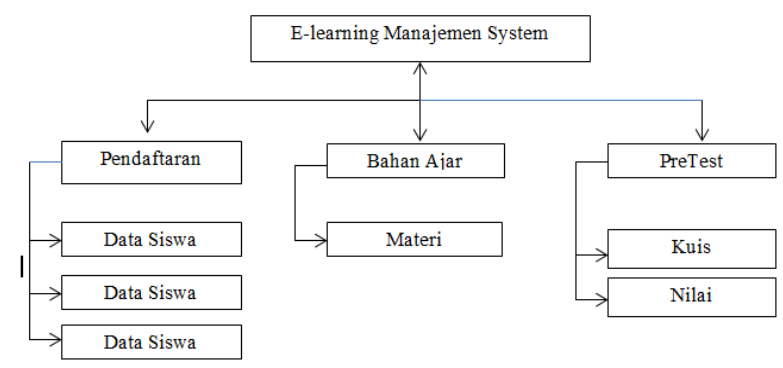

Gambar 1. Dekomposisi Fungsi Sistem yang Diusulkan 
Diagram aliran data (DAD) konteks, Nol, dan Rinci sistem yang Diusulkan

1. Diagram Konteks

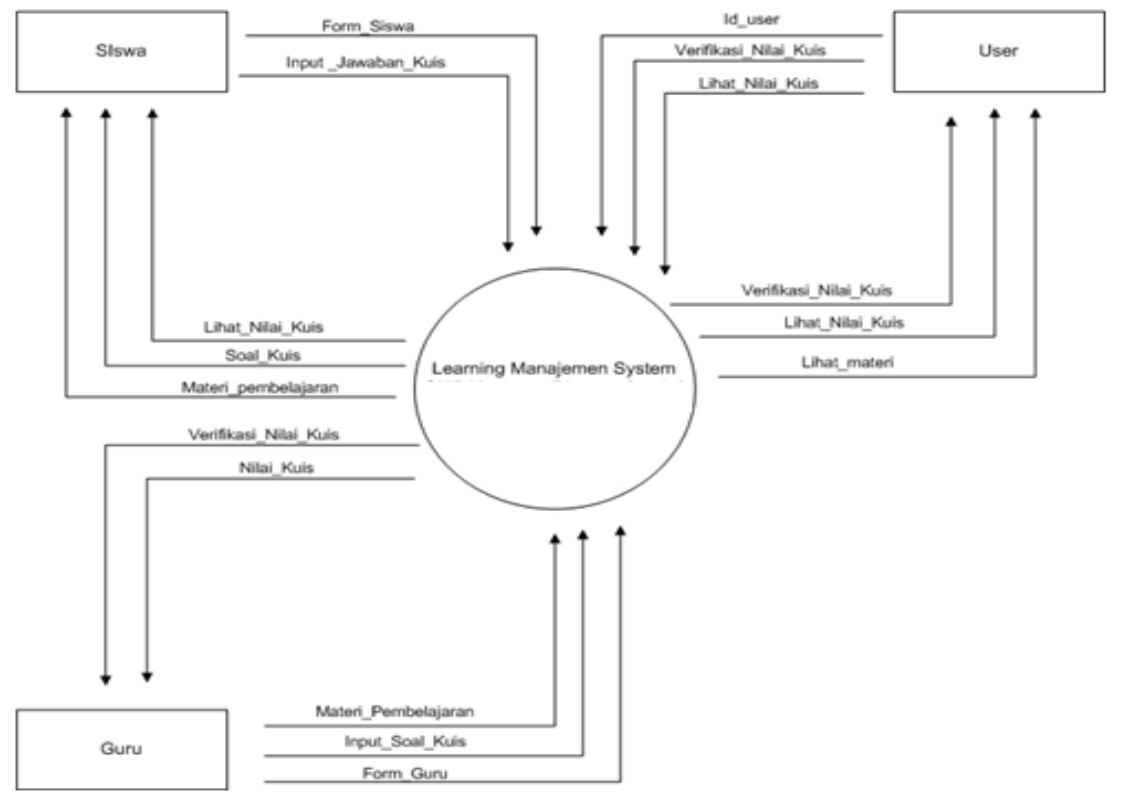

Gambar 2. Diagram Konteks untuk Sistem yang Diusulkan

2. Diagram Nol

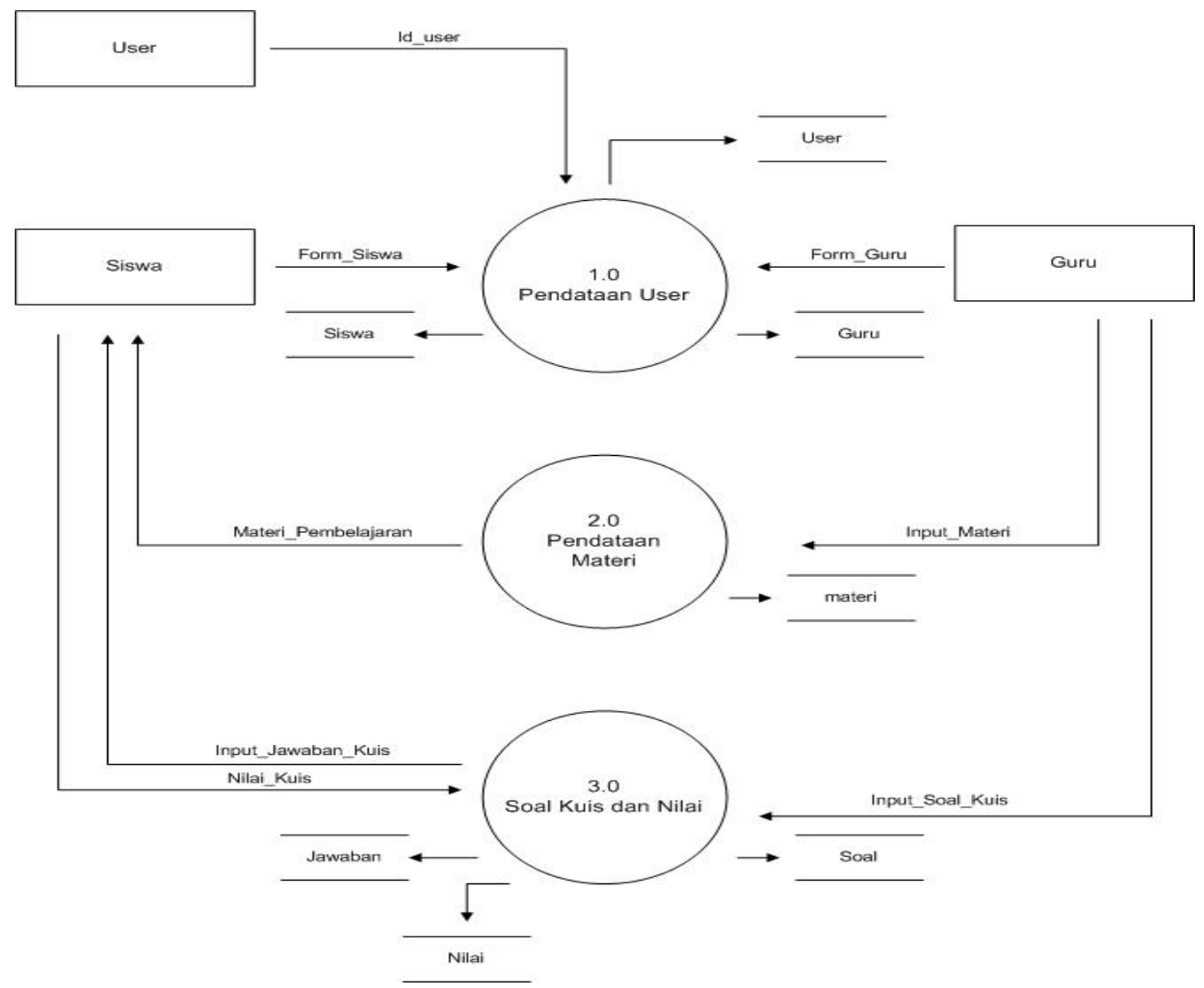

Gambar 3. Diagram Nol untuk Sistem yang Diusulkan 
3. Diagram rinci

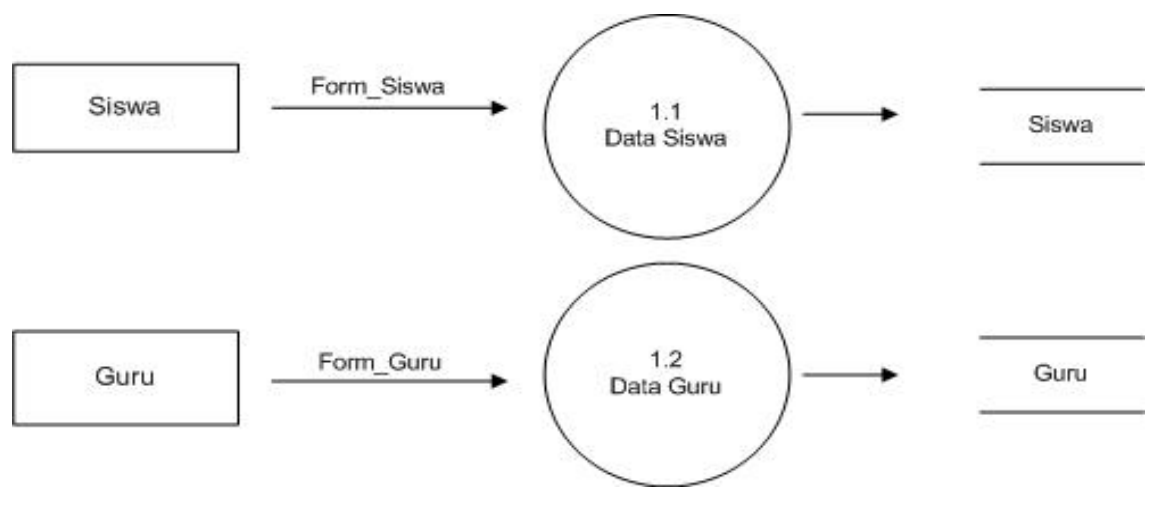

Gambar 4. Diagram Rinci Level -1 untuk Proses 1.0

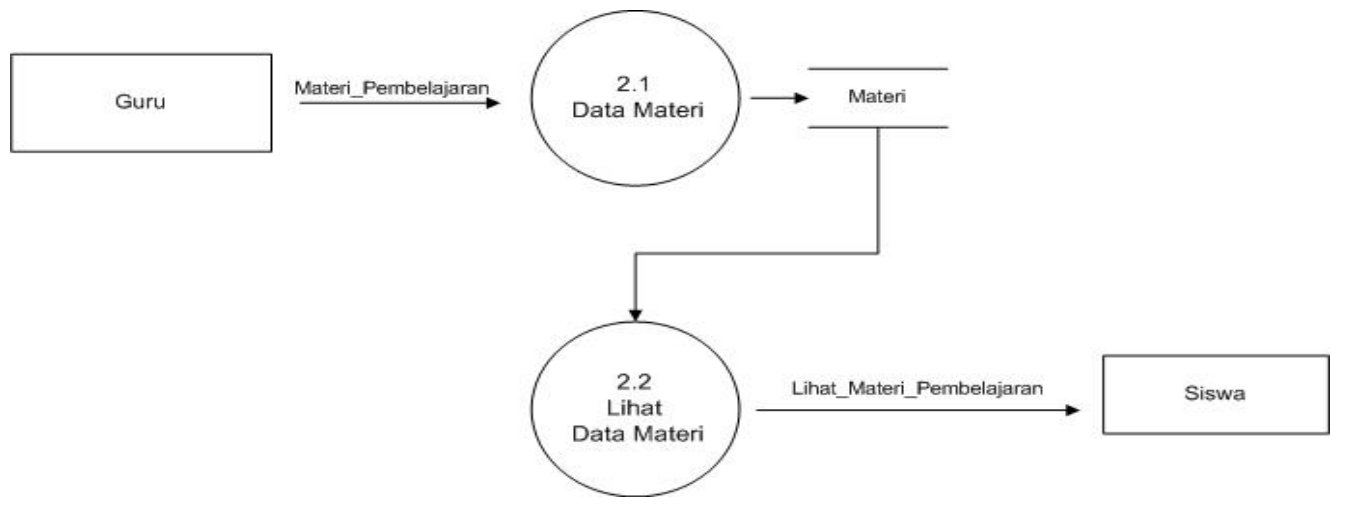

Gambar 5. Diagram Rinci Level -1 untuk Proses 2.0

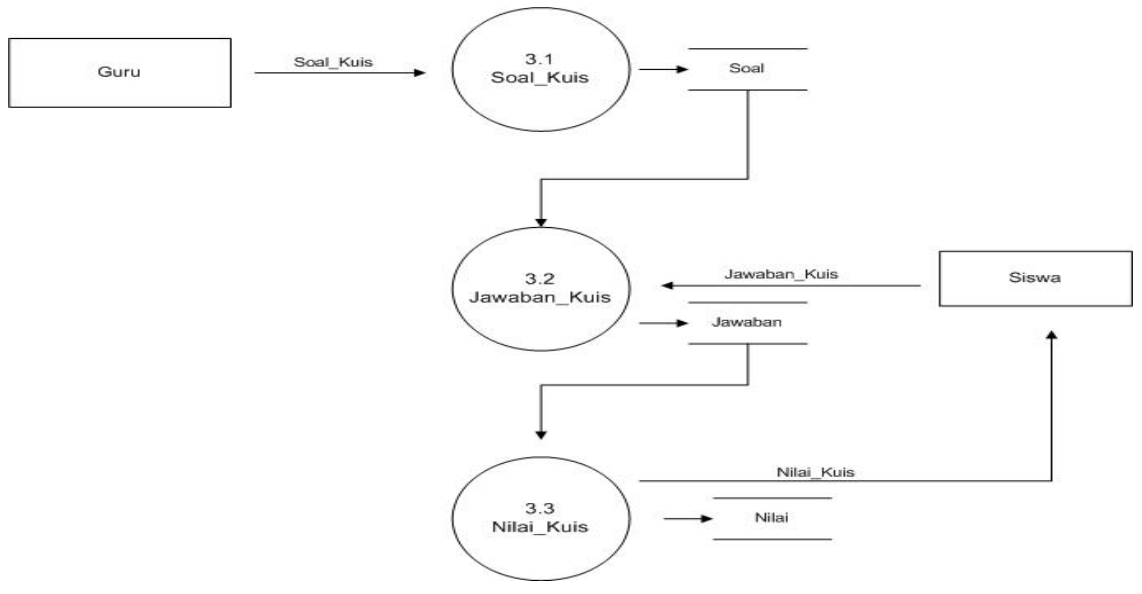

Gambar 6. Diagram Rinci Level -1 untuk Proses 3.0 


\section{Rancangan Basis Data yang Diusulkan}

Entity Relationship Diagram (ERD)

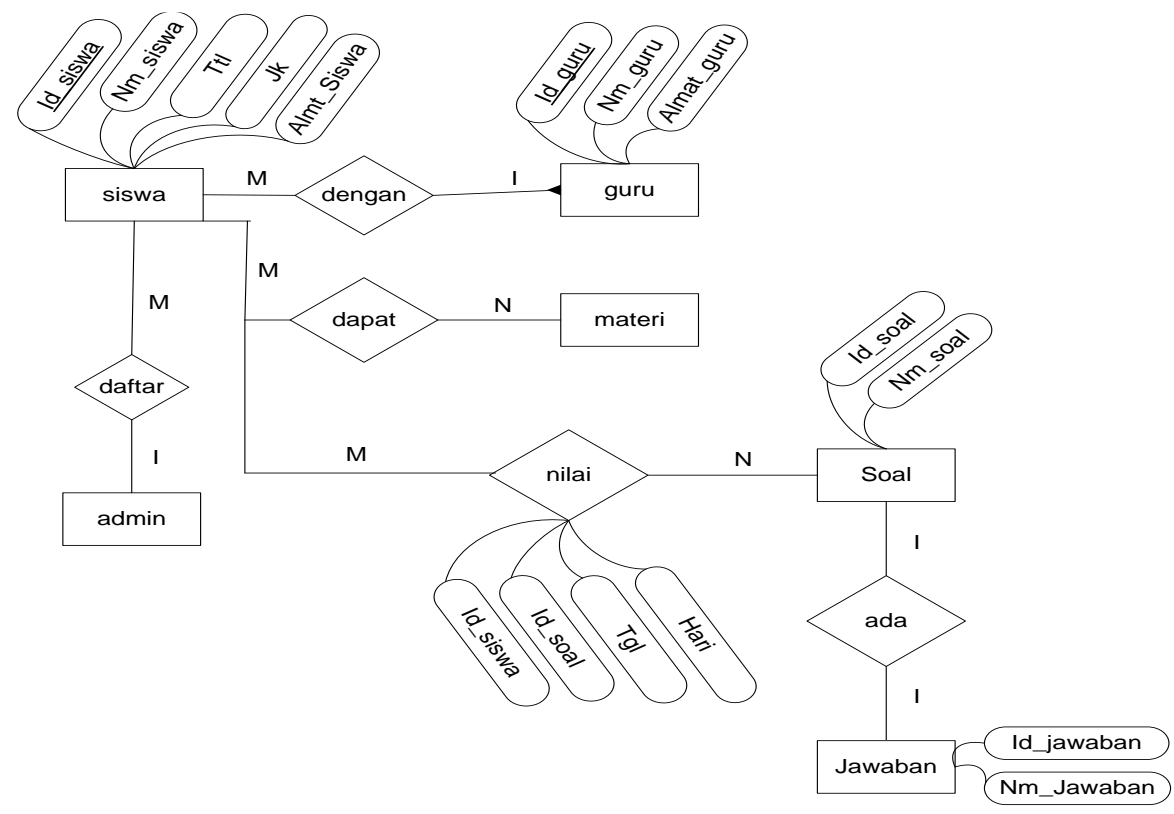

Gambar 7. Entity Relationship Diagram (ERD)

\section{Spesifikasi file yang diusulkan}

a. File Data Siswa

Nama file : data siswa

Primary key : id_siswa

Tabel 1. Data Siswa

\begin{tabular}{clll}
\hline No.Field & Nama field & Tipe (Panjang) & Keterangan \\
\hline 1 & Id_siswa & Varchar (5) & Identitas siswa \\
2 & Nm_siswa & Varchar (5) & Nama siswa \\
3 & Ttl & Varchar (225) & Tanggal lahir siswa \\
4 & Jk & Varchar (255) & Jenis kelamin \\
5 & Almt_siswa & Varchar (255) & Alamat siswa \\
\hline
\end{tabular}

Sumber : Data Diolah

b. File Data Guru

Nama file

: data guru

Primary key

: id_guru

Tabel 2. Data Guru

\begin{tabular}{clll}
\hline No.Field & Nama field & Tipe (Panjang) & Keterangan \\
\hline 1 & Id_guru & Varchar (11) & Identitas guru \\
2 & Nm_guru & Varchar (225) & Nama guru \\
3 & Almt_guru & Varchar (50) & Alamat guru \\
\hline
\end{tabular}

c. File Data Materi

Nama file

: data materi

Primary key

: id_materi

Foreigen key

: id_guru, id_siswa 
Tabel 3. Data Materi

\begin{tabular}{clll}
\hline No. Field & Nama field & Tipe (Panjang ) & Keterangan \\
\hline 1 & Id_materi & Varchar (225) & Identitas materi \\
2 & Nm_materi & Varchar (225) & Nama materi \\
3 & Id_guru & Varchar (225) & Identitas guru \\
4 & Id_siswa & Varchar (225) & Identitas siswa \\
\hline
\end{tabular}

d. File Data Soal

$\begin{array}{ll}\text { Nama file } & \text { : data soal } \\ \text { Primary key } & \text { : id_soal } \\ \text { Foreigen key } & \text { : id_siswa }\end{array}$

Tabel 4. Data Soal

\begin{tabular}{clll}
\hline No. Field & Nama field & Tipe (Panjang) & Keterangan \\
\hline 1 & Id_soal & Varchar $(225)$ & Identitas soal \\
2 & Nm_soal & Varchar (225) & Nama soal \\
3 & Id_siswa & Varchar (225) & Identitas siswa \\
\hline
\end{tabular}

e. File Data Jawaban
Nama file
: data jawaban
Primary key
: id_jawaban
Foreigen key
: id_siswa

Tabel 5. Data Jawaban

\begin{tabular}{clll}
\hline No. Field & Nama field & Tipe (Panjang) & Keterangan \\
\hline 1 & Id_jawaban & Varchar (225) & Identitas jawaban \\
2 & Nm_jawaban & Varchar (225) & Nama jawaban \\
3 & Id_siswa & Varchar (225) & Identitas siswa \\
\hline
\end{tabular}

\section{Hubungan Antar Tabel}

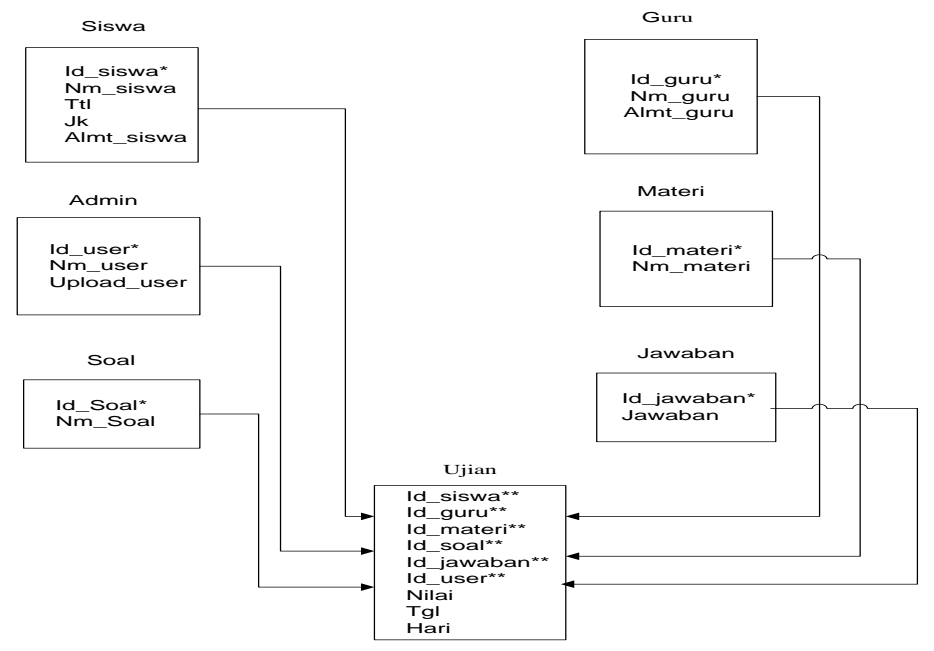

Gambar 8. Hubungan Antar Tabel 


\section{Simpulan dan Saran}

\section{Simpulan}

Berdasarkan hasil penelitian dan pembahasan dapat ditarik simpulan sebagai berikut :

1. Pembelajaran dengan E-Learning Manajemen System adalah suatu bentuk pembelajaran yang tidak terbatas waktu dan ruang dimana siswa yang belajar untuk menimba ilmu tidak harus secara fisik menghadiri kelas

2. Suatu E-Learning Manajemen System membutuhkan perancangan database karena database yang salah akan mengakibatkan informasi yang ingin dirancang tidak tersampaikan.

3. E-Learning Manajemen System dapat mempersingkat jadwal target waktu pembelajaran, menghemat biaya yang harus di keluarkan sebuah sekolah, mempermudahkan interaksi antara peserta didik dengan bahan/materi, peserta didik dengan guru/dosen/instruktur maupun peserta didik.

4. Peserta didik dapat saling berbagi informasi dan mengakses bahan-bahan belajar setiap saat dan berulang-ulang.

5. Fasilitas kerjasama online yang dimiliki E-Learning Manajemen System memudahkan berlangsungnya proses transfer informasi dan komunikasi.

6. Pembelajaran dengan dukungan teknologi internet membuat pusat perhatian dalam pembelajaran tertuju pada pembelajar, dan tidak bergantung sepenuhnya pada pengajar.

\section{Saran}

Guna mendukung dan mencapai tujuan perkembangan dalam sistem pendidikan, penulis memberikan saran diantaranya sebagai berikut :

1. Penyempurnaan desainware database dengan menggunakan software terbaru agar tampilan yang akan dibuat akan lebih menarik sipemakai

2. Software yang akan dibentuk bisa menambah fitur-fitur yang dapat menambah pengetahuan siswa dan guru.

\section{Daftar Pustaka}

Ellis, Ryann K. (2009). Field Guide to Learning Management Systems. ASTD Inc.

Kristanto, A. (2008). Perancangan Sistem Informasi dan Aplikasinya. Yogyakarta : Graha Ilmu.

Octafian. (2011). Desain Database Sistem Informasi Penjualan Barang (Studi Kasus : minimarket "Grace" Palembang). Jurnal Teknologi Dan Informatika (TEKNOMATIKA), Vol. 1 No.2 Tahun 2011, 148-157

Riduwan. (2005). Belajar mudah penelitian untuk Guru, Karyawan dan Peneliti Pemula. Bandung: Alfabeta.

Sutabri, T. (2012). Analisis Sistem Informasi. Jakarta: CV Andi Offset.

Yakub. (2012). Pengantar Sistem Informasi. Yogyakarta: Graha Ilmu. 